\title{
Effects of an adapted physical activity program on psychophysical health in elderly women
}

\author{
This article was published in the following Dove Press journal: \\ Clinical Interventions in Aging \\ 29 July 2016 \\ Number of times this article has been viewed
}

\author{
Giuseppe Battaglia ${ }^{1,2}$ \\ Marianna Bellafiore ${ }^{1,2}$ \\ Marianna Alesi',2 \\ Antonio Paoli ${ }^{3}$ \\ Antonino Bianco 1,2 \\ Antonio Palma ${ }^{1,2}$ \\ 'Department of Psychological, \\ Pedagogical and Educational Sciences, \\ ${ }^{2}$ Sport and Exercise Sciences Research \\ Unit, University of Palermo, Palermo, \\ ${ }^{3}$ Department of Biomedical Sciences, \\ University of Padova, Padua, Italy
}

Correspondence: Giuseppe Battaglia Department of Psychological, Pedagogical and Educational Sciences, University of Palermo, Via Giovanni Pascoli, 6, 90144 Palermo, Italy

$\mathrm{Tel}+3909123899616$

$\mathrm{Fax}+3909123860894$

Email giuseppe.battaglia@unipa.it
Background: Several studies have shown the positive effects of adapted physical activity (APA) on physical and mental health $(\mathrm{MH})$ during the lifetime. The aim of this study was to assess the effectiveness of a specific APA intervention program in the improvement of the health-related quality of life (QOL) and functional condition of spine in elderly women.

Methods: Thirty women were recruited from a senior center and randomly assigned to two groups: control group (CG; age: $69.69 \pm 7.94$ years, height: $1.57 \pm 0.06 \mathrm{~m}$, weight: $68.42 \pm 8.18 \mathrm{~kg}$, body mass index [BMI]: 27.88 \pm 2.81 ) and trained group (TG; age: $68.35 \pm 6.04$ years, height: $1.55 \pm 0.05$ m, weight: $64.78 \pm 10.16 \mathrm{~kg}$, BMI: $26.98 \pm 3.07)$. The APA program was conducted for 8 weeks, with two training sessions/week. CG did not perform any physical activity during the study. Spinal angles were evaluated by SpinalMouse ${ }^{\circledR}$ (Idiag, Volkerswill, Switzerland); health-related QOL was evaluated by SF-36 Health Survey, which assesses physical component summary (PCS-36), mental component summary (MCS-36), and eight subscales: physical functioning, role-physical, bodily pain, general health perception, role-emotional, social functioning, vitality, and MH. All measures were recorded before and after the experimental period.

Results: In TG, compared to CG, the two-way analysis of variance with repeated measures with Bonferroni post hoc test showed a relevant improvement in lumbar spinal angle $\left(^{\circ}\right)$ and in SF-36 outcomes after the intervention period. We showed a significant increase in physical functioning, bodily pain, and MH subscales and in PCS-36 and MCS-36 scores in TG compared to CG. In particular, from baseline to posttest, we found that in TG, the PCS-36 and MCS-36 scores increased by $13.20 \%$ and $11.64 \%$, respectively.

Conclusion: We believe that an 8-week APA intervention program is able to improve psychophysical heath in elderly people. During the aging process, a dynamic lifestyle, including regular physical activity, is a crucial factor for public and health care systems to improve QOL and physical fitness in aging people.

Keywords: quality of life, aging, stretching, spine, health, elderly people, exercise

\section{Introduction}

Independence and improvement of quality of life (QOL) in elderly people is needed in an aging society. The Italian population is aging quickly and, in agreement with Eurostat researches, Italy is among countries with the highest lifespan and life expectancy in Europe. During the past century, life expectancy rapidly increased due to a number of factors, including decrease in infant mortality, rising living standards, improved lifestyles and better education, as well as advances in adapted physical activity (APA), health care, and medicine. ${ }^{1}$ Several studies showed the positive effects of APA on physical and mental health $(\mathrm{MH})$ during the lifetime. ${ }^{2-5}$ Kovacs et $\mathrm{al}^{6}$ showed that a 25-week APA program improved static balance, functional mobility, as well as physical functioning (PF), vitality (VT), and general health subdomains of QOL 
in community-dwelling older women. An active lifestyle, including a regular physical activity during the aging process, is, therefore, a major challenge for public and health care systems to maintain a good health and physical fitness in the aging population. ${ }^{6}$ A recent study has shown that back muscle strength and spinal mobility are important predictors of QOL in the elderly. ${ }^{7}$ In particular, Imagama et $\mathrm{al}^{7}$ showed that exercise training programs, including muscle strength and spinal range of motion (ROM) could influence sagittal balance, lumbar lordosis angle, spinal ROM, and back muscle strength that are known to be related to better QOL. Back muscle strength and thoracic ROM have an impact on the improvement of QOL in the middle-aged and the elderly. We found in a previous study ${ }^{8}$ that elderly women who performed exercises recommended by a specific flexibility APA program could improve ROMs in specific regions of the spine. Particularly, after 8 weeks of APA, participants showed an increased spinal ROM compared to the control group (CG).

It is widely recognized by researchers and practitioners that physical activity affects QOL in old age via three psychological hypotheses: 1) distraction, 2) self-efficacy, and 3) social relationships. ${ }^{9}$ First, the enjoyable nature of physical activities acts as a distraction from unfavorable daily life experiences and improves the mood after exercises. Second, the motivation to complete a physically challenging task was found to be a very important factor for increasing selfconcept, self-awareness, and self-determination. ${ }^{10}$ Third, physical activities create opportunities of social interaction, cooperation with others, respecting rules, sharing leisure experiences, and receiving the encouragement of peers.

For these reasons, the main purpose of this study was to investigate the effects of an 8-week flexibility training APA program on health-related QOL and spinal angles in the elderly. In agreement with Imagama et al, ${ }^{11}$ we hypothesized that our APA training program ${ }^{8}$ might improve QOL and spine health among healthy elderly.

\section{Methods}

\section{Participants}

Participants were healthy volunteers who attended the local project "Volare" at a senior center in Palermo (Sicily) in 2012. We carried out the experiments on the same subjects participating in a previous study, in which we had observed that an 8-week flexibility training program could improve the ROM in specific regions of the spine in elderly women. ${ }^{8}$

Subjects were regarded appropriate for the study if they met all of the following inclusion criteria: 1) $\geq 60$ years of chronological age, 2) capacity of providing informed consent for study participation, 3) suitability for practicing physical activity as attested by medical certificate, 4 ) stated capability in self-care and normal household tasks, 5) availability to attend at least $80 \%$ of the training sessions, 6 ) declared autonomy, 7) at least 6 months of a programmed physical activity in order to recruit active elderly people, and 8) no falls in the last year.

Participants were excluded from the study if they had severe walking or standing disabilities ${ }^{12}$ and scored $<45$ in the Berg balance scale.

Forty-one woman and four male subjects accepted to attend the program but only women were recruited; however, after the interview, it was found that only 37/41 women met all the inclusion criteria and were considered appropriate for this study. Subjects were randomly assigned to two groups using a random numbers table: $\mathrm{CG}$ and $\mathrm{TG}$, which included 18 and 19 women, respectively. TG was trained for 8 weeks, while CG did not perform any organized physical activity during the experimental period. Evaluations were performed thrice in the morning, and the average value was used for statistical analysis. The same researcher took all the measurements. In data evaluation, two participants from the TG were excluded from the study because they did not attend $80 \%$ of the training sessions; five subjects of the CG were not considered as they were not subjected to the posttest because of personal reasons. For these reasons, 30 women, including 13 not-trained subjects of CG (age: $69.69 \pm 7.94$ years, height: $1.57 \pm 0.06 \mathrm{~m}$, weight: $68.42 \pm 8.18 \mathrm{~kg}$, body mass index [BMI]: $27.88 \pm 2.81$ ) and 17 trained subjects of TG (age: $68.35 \pm 6.04$ years, height: $1.55 \pm 0.05 \mathrm{~m}$, weight: $64.78 \pm 10.16 \mathrm{~kg}$, BMI: $26.98 \pm 3.07$ ), were included in the statistical analysis. Moreover, all trained participants $(n=19$; age: $67.68 \pm 6.03$ years, height: $1.54 \pm 0.05 \mathrm{~m}$, weight: $64.34 \pm 10.02 \mathrm{~kg}, \mathrm{BMI}$ : 26.91 \pm 3.00 ) were included in the "intention to treat" (ITT) approach to make our analysis exhaustive.

All participants gave their written informed consent prior to starting the study. This study was approved by Commissione Etica del Dipartimento DISMOT [Ethics Commission of the Department DISMOT]. The study was conducted in accordance with the principles of the Declaration of Helsinki.

\section{Anthropometric measurements}

Bodyweight was assessed using a Seca electronic scale (maximum weight recordable $300 \mathrm{~kg}$; resolution $100 \mathrm{~g}$; Seca; Hamburg, Germany) with the subjects wearing only their underwear. Height was measured by a standard stadiometer (maximum height recordable $220 \mathrm{~cm}$; resolution $1 \mathrm{~mm}$ ) with the subjects barefoot and standing upright. BMI was estimated as bodyweight divided by height squared $\left(\mathrm{kg} / \mathrm{m}^{2}\right)$. 


\section{Measurement of spinal angles}

Spinal angles was evaluated by SpinalMouse ${ }^{\circledR}$ (Idiag, Volkerswill, Switzerland), which is an electronic computeraided device that measures intersegmental angles in a noninvasive technique. ${ }^{13}$ The SpinalMouse was run paravertebrally along the spine from the seventh cervical (C7) to the third sacral (S3) vertebra. We measured thoracic spine angle $\left(\right.$ Thor $\left.\mathrm{Sp}^{\circ}\right)$, lumbar spine angle $\left(\operatorname{Lum~Sp}{ }^{\circ}\right.$ ), spinal inclination (Inclin ${ }^{\circ}$ ), and sacral/hip angle in a neutral standing position. All the assessments were performed thrice but only the average value was provided for statistical analysis. The same investigator took all the measurements and lordotic angles were expressed as negative values, while kyphotic angles were expressed as positive values. Participants did not perform "warming up" before the assessment. Intraclass coefficients of $0.89-0.95$ were determined for curvature measurement with SpinalMouse.

\section{Adapted physical activity intervention program}

The training program was conducted for 8 weeks, with two training sessions/week. Every training session included a warm-up phase ( $\sim 10$ minutes), a central period ( $\sim 50$ minutes), and cool-down phase ( $\sim 10$ minutes). In the warm-up phase, from standing posture, participants executed a standard sequence of exercises, including circling movements of shoulders, pelvis and feet, trunk rotations, and free walking. In the central period phase, subjects performed twice a specific training mesocycle with a sinusoidal pattern (Figure 1) of training volume (sets and repetitions of exercises). We included in the central phase several training exercises for flexibility of the spine, core stability, and stretching of upper and lower body, such as trunk rotations, sit-up exercises, and stretching exercises of lower and upper limbs. ${ }^{8}$

As seen in Figure 1, the training volume increased from the first to the third week and from the fifth to the seventh week; in the fourth and eighth weeks the training volume was reduced, decreasing the complexity, sets and repetitions of several exercises. The cool-down phase included a standard sequence of stretching exercises, such as: from a kneeling position, slowly going back on the heels; from a supine posture, pull the knee toward the body; from neutral standing position, bend the whole body forward slowly. ${ }^{8}$

\section{Assessment of health-related QOL}

Health-related QOL was evaluated by the SF-36 Health Survey, which assesses participants self-reported health QOL using physical and mental composite scores. It investigated two dimensions: physical component summary (PCS-36, physical domain of SF-36, scores ranging from 0 to 100) and mental component summary (MCS-36, mental domain of SF-36, scores ranging from 0 to 100). In particular, this questionnaire measures health-related functions along eight subscales: PF, role-physical (RP) limitations caused by physical problems, bodily pain (BP), general health perception $(\mathrm{GH})$, role-emotional (RE) limitations caused by emotional problems, social functioning (SF), VT, and MH. Specifically, the PF, RP, BP, and GH belong to the physical component, while VT, SF, RE, and MH belong to the mental component. PCS and MCS of the SF-36 showed good internal consistency and reliability, with alpha coefficients of 0.82 and 0.79 , respectively. The MCS and the PCS were scored with

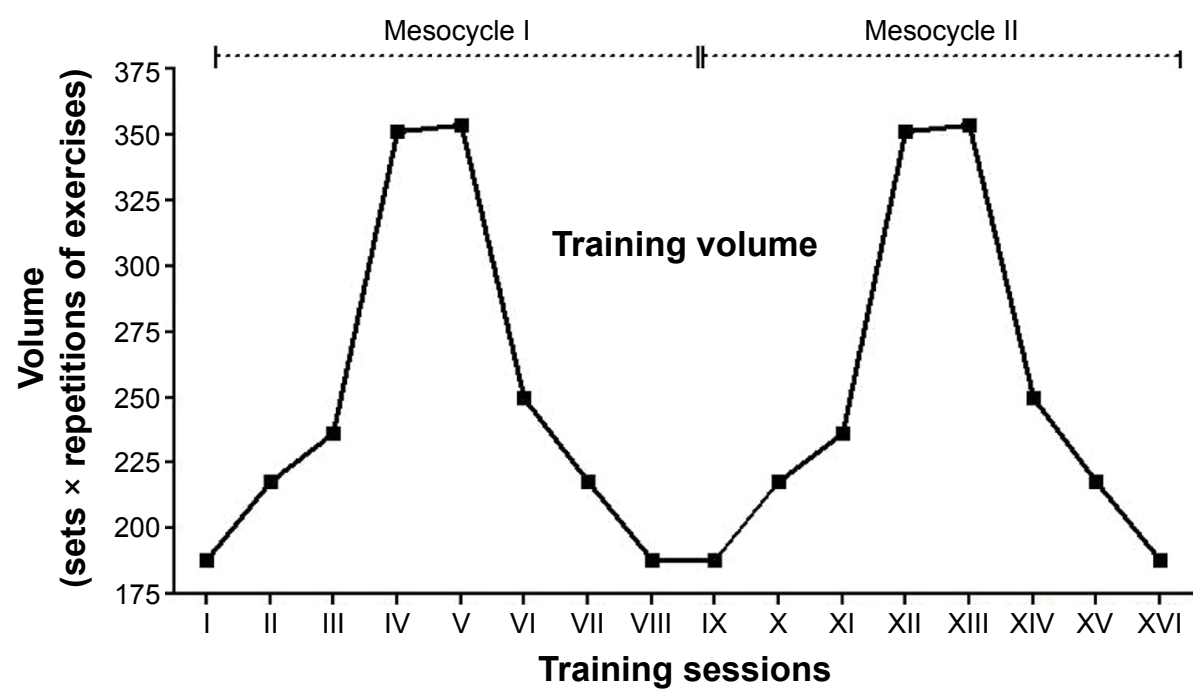

Figure I The training volume of the adapted physical activity intervention program. 
norm-based methods. All data were acquired before (pretest) and after (posttest) the experiment.

\section{Statistical analysis}

Results were expressed as mean \pm standard deviation. Twoway analysis of variance (ANOVA) with repeated measures was used to evaluate differences over time in anthropometric parameters, spinal measures, and physical and mental composite scores of the SF-36 Health Survey between CG and TG in response to treatment using the "per protocol" and ITT approaches. Time (baseline-posttest)*group (control-trained) interaction was considered and the Bonferroni correction was applied as post hoc test. To examine between-group differences at baseline, $t$-tests of independent samples were conducted for anthropometric parameters, spinal measures, and physical and mental composite scores of the SF-36 Health Survey. The mean differences and $95 \%$ confidence intervals were calculated for the experimental group and the $\mathrm{CG}$. Statistical significance was accepted as $P<0.05$. Levene's test was used to assess the homogeneity of variance. All data were evaluated using STATISTICA 8.0 Software, version 10 (Statsoft Inc, Tulsa, OK, USA).

\section{Results}

Data analysis showed a normal distribution of variance for each dependent variable. As published in our previous study, ${ }^{8}$ we observed that, both at baseline and after the 8-week period, CG and TG did not show any significant difference in bodyweight, height, and BMI. Moreover, at baseline, the two groups were equivalent in Thor $\mathrm{Sp}^{\circ}, \operatorname{Lum~} \mathrm{Sp}^{\circ}$, Inclin ${ }^{\circ}$, and sacral/hip angle (Table 1).

The two-way ANOVA with repeated measures with Bonferroni post hoc test showed a relevant decrease in Lum $\mathrm{Sp}^{\circ}$ in $\mathrm{TG}$ compared to $\mathrm{CG}$ after the training period (Table 2). However, time (baseline-posttest)*group (control-trained) interaction did not show any significant difference in $\mathrm{TG}$ compared to CG. Otherwise, TG did not show any significant difference in Thor $\mathrm{Sp}^{\circ}$, Inclin ${ }^{\circ}$, and sacral/hip angle compared to CG (Table 2).

Regarding measurements from SF-36 Health Survey, we observed, at baseline, that TG and CG were equivalent in health-related functions along eight subscales (PF, RP limitations; BP, GH, RE limitations; SF, VT, and MH subscales) and PCS-36 and MCS-36. We found that after the training period, all eight subscales of SF-36 Health Survey increased in TG compared to CG (Table 2). In particular, the two-way ANOVA with repeated measures with Bonferroni post hoc test showed a significant increase in $\mathrm{PF}(P=0.001)$,
Table I Characteristics of cohort at baseline

\begin{tabular}{llll}
\hline SF-36 & CG & TG & $\begin{array}{l}\text { Baseline } \\
(\boldsymbol{P} \text {-value })\end{array}$ \\
\hline PF & $81.92 \pm 7.30$ & $75.59 \pm 10.44$ & $\mathrm{~ns}$ \\
RP & $94.23 \pm 14.98$ & $83.82 \pm 23.29$ & $\mathrm{~ns}$ \\
BP & $77.46 \pm 21.44$ & $68.00 \pm 21.78$ & $\mathrm{~ns}$ \\
GH & $62.85 \pm 17.50$ & $63.29 \pm 20.15$ & $\mathrm{~ns}$ \\
VT & $68.85 \pm 10.24$ & $73.53 \pm 9.96$ & $\mathrm{~ns}$ \\
SF & $83.62 \pm 18.66$ & $77.21 \pm 22.20$ & $\mathrm{~ns}$ \\
RE & $84.62 \pm 22.00$ & $76.46 \pm 30.67$ & $\mathrm{~ns}$ \\
MH & $74.46 \pm 17.78$ & $66.59 \pm 15.42$ & $\mathrm{~ns}$ \\
PCS & $48.48 \pm 6.54$ & $47.36 \pm 5.13$ & $\mathrm{~ns}$ \\
MCS & $51.55 \pm 7.83$ & $49.18 \pm 8.12$ & $\mathrm{~ns}$ \\
Thor Sp $\left(^{\circ}\right)$ & $62.42 \pm 8.96$ & $61.85 \pm 12.45$ & $\mathrm{~ns}$ \\
Lum Sp $\left({ }^{\circ}\right)$ & $-32.31 \pm 5.80$ & $-32.21 \pm 5.21$ & $\mathrm{~ns}$ \\
Sacral/hip $\left(^{\circ}\right)$ & $12.34 \pm 6.13$ & $12.18 \pm 6.73$ & $\mathrm{~ns}$ \\
Inclin $\left({ }^{\circ}\right)$ & $0.08 \pm 3.24$ & $1.24 \pm 3.17$ & $\mathrm{~ns}$ \\
\hline Note & &
\end{tabular}

Notes: Data presented as mean \pm standard deviation. Kyphotic values are positive; lordotic values are negative.

Abbreviations: BP, bodily pain; CG, control group; GH, general health perception; Inclin, spinal inclination; Lum Sp, lumbar spine; MCS, mental component summary; $\mathrm{MH}$, mental health; PCS, physical component summary; PF, physical functioning; RP, role-physical limitations caused by physical problems; RE, role-emotional limitations caused by emotional problems; Sac/Hip, sacral/hip; SF, social functioning; TG, trained group; Thor $\mathrm{Sp}$, thoracic spine; VT, vitality; ns, not significant.

BP $(P=0.007)$, and $\mathrm{MH}(P=0.001)$ subscales and in PCS $(P=0.007)$ and $\operatorname{MCS}(P=0.006)$ scores in TG compared to $\mathrm{CG}$ after the training period (Table 2). Moreover, the ITT analysis showed results similar to the "per protocol", as is evident from Table 3. From baseline to posttest, PCS-36 and MCS-36 scores increased by $13.20 \%$ and $11.64 \%$, respectively, in the TG (Figures 2 and 3).

\section{Discussion}

In our precedent study, we showed that elderly women who took part in the special flexibility training program enhanced ROMs in specific regions of the spine. Especially, after the training period, participants reported an improved total thoracic ROM in the spine. In the present study, two-way ANOVA with repeated measures with Bonferroni post hoc test showed a relevant decrease in $\operatorname{Lum~} \mathrm{Sp}^{\circ}$ (18.53\%) and spinal inclination $(54.84 \%)$ in the exercised group after the training period (Table 2). Moreover, we did not show any significant difference in Thor Sp and sacral/hip angles in the exercised group compared to control (Table 2). We suggest that our APA intervention program could prevent the onset of "locomotive syndrome" in elderly, as suggested in the study of Hirano et al. ${ }^{12}$ Hirano et al $^{12}$ showed that an increase in spinal inclination and a decrease in back muscle strength were significantly associated with locomotive syndrome. The Japanese Orthopaedic Association proposed the term 
Table 2 Per protocol analysis of SF-36 subscales and spinal angles in response to the training program

\begin{tabular}{|c|c|c|c|c|c|c|c|c|c|}
\hline \multirow[t]{2}{*}{ SF-36 } & \multicolumn{4}{|c|}{ Control group } & \multicolumn{4}{|c|}{ Trained group } & \multirow{2}{*}{$\begin{array}{l}\text { Group } \\
\times \text { time } \\
\text { (P-value) }\end{array}$} \\
\hline & BT & AT & $\begin{array}{l}\text { BT vs } \\
\text { AT } \\
\text { (P-value) }\end{array}$ & $\begin{array}{l}\text { Difference, mean } \\
(95 \% \mathrm{Cl})\end{array}$ & $\overline{\text { BT }}$ & AT & $\begin{array}{l}\text { BT vs } \\
\text { AT } \\
\text { (P-value) }\end{array}$ & $\begin{array}{l}\text { Difference, mean } \\
(95 \% \mathrm{Cl})\end{array}$ & \\
\hline PF & $81.92 \pm 7.23$ & $85.00 \pm 12.42$ & ns & 3.07 (-4.74 to 10.90$)$ & $75.59 \pm 10.44$ & $92.06 \pm 6.39$ & 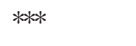 & $16.47(9.62$ to -23.31$)$ & $* *$ \\
\hline RP & $94.23 \pm 14.98$ & $92.31 \pm 15.76$ & ns & $-1.92(-20.53$ to 16.69$)$ & $83.82 \pm 23.29$ & $98.53 \pm 6.06$ & ns & $14.70(-1.57$ to 30.98$)$ & ns \\
\hline BP & $77.46 \pm 21.44$ & $69.77 \pm 23.05$ & ns & $-7.69(-28.39$ to 13.01$)$ & $68.00 \pm 21.78$ & $88.24 \pm 14.63$ & $*$ & $20.23(-2.13$ to -38.34$)$ & $* *$ \\
\hline $\mathrm{GH}$ & $62.85 \pm 17.50$ & $63.92 \pm|3.3|$ & ns & $1.07(-14.52$ to I6.68) & $63.29 \pm 20.15$ & $78.4 I \pm \mid 3.78$ & $*$ & I5.II (I.46 to 28.76$)$ & ns \\
\hline VT & $68.85 \pm 10.24$ & $73.46 \pm 9.66$ & ns & 4.61 ( -4.93 to 14.16$)$ & $73.53 \pm 9.96$ & $82.94 \pm 10.32$ & $*$ & 9.41 (1.06 to I7.76) & ns \\
\hline SF & $83.62 \pm 18.66$ & $85.58 \pm 14.29$ & ns & $1.96(-10.06$ to 13.99$)$ & $77.21 \pm 22.20$ & $85.24 \pm|4.8|$ & ns & $8.02(-2.49$ to 18.54$)$ & ns \\
\hline RE & $84.62 \pm 22.00$ & $87.19 \pm 16.86$ & ns & 2.56 (-20.93 to 26.07$)$ & $76.46 \pm 30.67$ & $100 \pm 0.0$ & $*$ & 23.53 (2.98 to 44.09$)$ & ns \\
\hline $\mathrm{MH}$ & $74.46 \pm 18.44$ & $74.46 \pm 17.78$ & ns & $0.0(-10.58$ to 10.58$)$ & $66.59 \pm 15.42$ & $84.47 \pm 9.68$ & $* * * *$ & $17.88(8.62$ to 27.13$)$ & $* *$ \\
\hline PCS & $48.48 \pm 6.54$ & $49.3 I \pm 6.82$ & ns & 0.82 (-3.23 to 4.87$)$ & $47.36 \pm 5.13$ & $53.61 \pm 3.33$ & 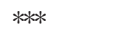 & 6.25 (2.70 to 9.79$)$ & $* *$ \\
\hline MCS & $51.55 \pm 7.83$ & $52.16 \pm 6.43$ & ns & 0.61 (-3.65 to 4.88$)$ & $49.18 \pm 8.12$ & $55.66 \pm 4.38$ & 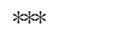 & $6.48(-2.75$ to 10.22$)$ & $* *$ \\
\hline Thor Sp $\left({ }^{\circ}\right)$ & $62.42 \pm 8.96$ & $66.31 \pm 9.82$ & ns & 3.88 (-3.05 to 10.82$)$ & $61.85 \pm 12.45$ & $59.82 \pm 12.24$ & ns & $-2.02(-8.09$ to 4.03$)$ & ns \\
\hline Lum Sp $\left({ }^{\circ}\right)$ & $-32.31 \pm 5.80$ & $-28.38 \pm 6.38$ & ns & $3.92(-0.86$ to $8.7 I)$ & $-32.2 I \pm 5.21$ & $-26.24 \pm 7.49$ & $* *$ & $5.97(1.78$ to 10.15$)$ & ns \\
\hline Sacral/hip $\left({ }^{\circ}\right)$ & $12.34 \pm 6.13$ & $8.81 \pm 7.49$ & ns & $-3.53(-8.02$ to 0.94$)$ & $12.18 \pm 6.73$ & $8.65 \pm 6.23$ & ns & $-3.52(-7.45$ to 0.39$)$ & ns \\
\hline Inclin $\left(^{\circ}\right)$ & $0.08 \pm 3.24$ & $1.69 \pm 3.54$ & ns & I.6I (-0.83 to 4.06$)$ & $1.24 \pm 3.17$ & $0.56 \pm 2.65$ & ns & $-0.67(-2.82$ to 1.46$)$ & ns \\
\hline
\end{tabular}

Notes: Data presented as mean \pm standard deviation. $* P<0.05 ; * * P<0.01 ; * * * P<0.001$. Kyphotic values are positive; lordotic values are negative.

Abbreviations: AT, after training; BT, before training; BP, bodily pain; CG, control group; Cl, confidence interval; GH, general health perception; Inclin, spinal inclination; Lum Sp, lumbar spine; MCS, mental component summary; MH, mental health; PCS, physical component summary; PF, physical functioning; RP, role-physical limitations caused by physical problems; RE, role-emotional limitations caused by emotional problems; Sac/Hip, sacral/hip; SF, social functioning; TG, trained group; Thor Sp, thoracic spine; VT, vitality; ns, not significant.

"locomotive syndrome" to describe a pathological condition of the elderly caused by weakening of the musculoskeletal organs, such as bones, joints, and muscles. Back muscle strength had significant negative correlations with age and spinal inclination. It had significant negative correlations with back muscle strength and lumbar and total spinal ROM and significant positive correlations with age, BMI, sacral slope angle, and lumbar kyphosis. A decrease in back muscle strength and an increase in spinal inclination may be the most important risk factors for locomotive syndrome in Japanese

Table 3 ITT analysis of SF-36 subscales and spinal angles in response to the training program

\begin{tabular}{|c|c|c|c|c|c|c|c|c|c|}
\hline \multirow[t]{2}{*}{ SF-36 } & \multicolumn{4}{|c|}{ Control group } & \multicolumn{4}{|c|}{ Trained group } & \multirow{2}{*}{$\begin{array}{l}\text { Group } \\
\times \text { time } \\
\text { (P-value) }\end{array}$} \\
\hline & $\overline{\text { BT }}$ & AT & $\begin{array}{l}\text { BT vs } \\
\text { AT } \\
\text { (P-value) }\end{array}$ & $\begin{array}{l}\text { Difference, mean } \\
(95 \% \mathrm{Cl})\end{array}$ & $\overline{\text { BT }}$ & AT & $\begin{array}{l}\text { BT vs } \\
\text { AT } \\
\text { (P-value) }\end{array}$ & $\begin{array}{l}\text { Difference, mean } \\
(95 \% \mathrm{Cl})\end{array}$ & \\
\hline PF & $81.92 \pm 7.23$ & $85.00 \pm 12.42$ & ns & 3.07 (-4.54 to 10.69$)$ & $76.84 \pm 10.57$ & $92.63 \pm 6.32$ & 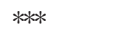 & I5.78 (9.48 to 22.09$)$ & *** \\
\hline RP & $94.23 \pm 14.98$ & $92.31 \pm 15.76$ & ns & $-1.92(-20.03$ to 16.19$)$ & $85.53 \pm 22.54$ & $98.68 \pm 5.74$ & ns & 13.15 (-1.82 to 28.14$)$ & ns \\
\hline BP & $77.46 \pm 21.44$ & $69.77 \pm 23.05$ & ns & $-7.69(-28.10$ to 12.72$)$ & $68.42 \pm 20.57$ & $87.42 \pm 15.44$ & $*$ & $19.00(-2.11$ to -35.88$)$ & ns \\
\hline $\mathrm{GH}$ & $62.85 \pm 17.50$ & $63.92 \pm|3.3|$ & ns & I.07 $(-|4.6|$ to 16.76$)$ & $64.63 \pm 19.42$ & $77.37 \pm 13.54$ & ns & $12.73(-0.23$ to $25.7 \mid)$ & ns \\
\hline VT & $68.85 \pm 10.24$ & $73.46 \pm 9.66$ & ns & $4.6 \mathrm{I}(-4.78$ to $14.0 \mathrm{I})$ & $74.21 \pm 9.96$ & $82.89 \pm 10.04$ & $*$ & $8.68(0.9 \mid$ to 16.45$)$ & ns \\
\hline SF & $83.62 \pm 18.66$ & $85.58 \pm 14.29$ & ns & $1.96(-9.98$ to 13.91$)$ & $79.61 \pm 22.13$ & $86.13 \pm 14.37$ & ns & $6.052(-3.35$ to $\mid 6.4 I)$ & ns \\
\hline RE & $84.62 \pm 22.00$ & $87.19 \pm 16.86$ & ns & $2.56(-20.46$ to 25.60$)$ & $77.19 \pm 29.52$ & $98.25 \pm 7.64$ & $*$ & 21.05 (2.00 to 40.11$)$ & ns \\
\hline $\mathrm{MH}$ & $74.46 \pm 18.44$ & $74.46 \pm 17.78$ & ns & $0.0(-10.38$ to 10.38$)$ & $68.00 \pm 15.66$ & $84.84 \pm 9.58$ & $* * *$ & I6.84 (8.25 to 25.42$)$ & $* *$ \\
\hline PCS & $48.48 \pm 6.54$ & $49.31 \pm 6.82$ & ns & $0.82(-3.21$ to 4.86$)$ & $47.84 \pm 5.09$ & $53.56 \pm 3.14$ & 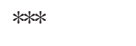 & 5.71 (2.37 to 9.05$)$ & $*$ \\
\hline MCS & $51.55 \pm 7.83$ & $52.16 \pm 6.43$ & ns & 0.61 ( -3.67 to 4.90$)$ & $49.78 \pm 8.05$ & $55.62 \pm 4.27$ & 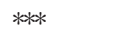 & 5.84 (-2.29 to 9.38$)$ & $*$ \\
\hline Thor Sp $\left({ }^{\circ}\right)$ & $62.42 \pm 8.96$ & $66.31 \pm 9.82$ & ns & $3.88(-2.78$ to 10.55$)$ & $61.97 \pm 11.84$ & $59.95 \pm I 1.62$ & ns & $-2.02(-7.54$ to 3.49$)$ & ns \\
\hline Lum Sp $\left(^{\circ}\right)$ & $-32.31 \pm 5.80$ & $-28.38 \pm 6.38$ & ns & $3.92(-0.84$ to 8.69$)$ & $-32.13 \pm 4.96$ & $-26.84 \pm 7.34$ & *** & $5.28(1.34$ to 9.23$)$ & ns \\
\hline Sacral/hip $\left({ }^{\circ}\right)$ & $12.34 \pm 6.13$ & $8.81 \pm 7.49$ & ns & $-3.53(-7.95$ to 0.87$)$ & $12.16 \pm 6.36$ & $9.08 \pm 6.02$ & ns & $-3.07(-6.72$ to 0.57$)$ & ns \\
\hline Inclin $\left({ }^{\circ}\right)$ & $0.08 \pm 3.24$ & $1.69 \pm 3.54$ & ns & I.6I $(-0.83$ to 4.06$)$ & $1.34 \pm 3.01$ & $0.79 \pm 2.75$ & ns & $-0.55(-2.57$ to 1.47$)$ & ns \\
\hline
\end{tabular}

Notes: Data presented as mean \pm standard deviation. $* P<0.05$; $* * P<0.01$; $* * * P<0.001$. Kyphotic values are positive; lordotic values are negative.

Abbreviations: AT, after training; BT, before training; BP, bodily pain; CG, control group; Cl, confidence interval; GH, general health perception; Inclin, spinal inclination; Lum Sp, lumbar spine; MCS, mental component summary; MH, mental health; PCS, physical component summary; PF, physical functioning; RP, role-physical limitations caused by physical problems; RE, role-emotional limitations caused by emotional problems; Sac/Hip, sacral/hip; SF, social functioning; TG, trained group; Thor Sp, thoracic spine; VT, vitality; ns, not significant. 


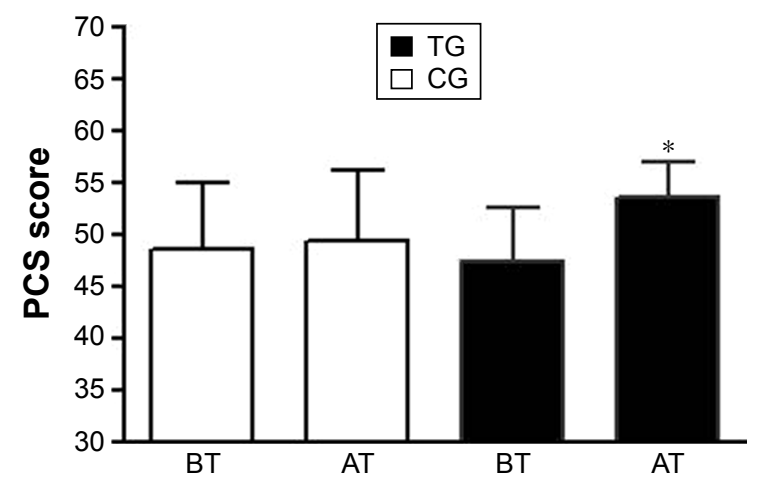

Figure 2 Mean score of physical component summary (PCS-36) of the SF-36 Health Survey in the BT and AT period in TG and CG.

Note: $* P<0.05$.

Abbreviations: BT, before training; AT, after training; TG, trained group; CG, control group; PCS, physical component summary; SF, short form.

men. In agreement with Hirano et al, back muscle strengthening and spinal ROM exercises, such as that included in our APA protocol, could be useful for improving the symptoms of locomotive syndrome. Our training exercise program determined significant improvements in health status indicators. This result is consistent with the growing research demonstrating that interventions based on ordinary physical activity are key elements to prevent diseases and to promote physical and emotional well-being in old age. ${ }^{14}$ From baseline to posttest, PCS-36 and MCS-36 scores increased by $13.20 \%$ and $11.64 \%$, respectively, in the TG compared to CG (Figures 2 and 3), as demonstrated by the two-way ANOVA with repeated measures (Table 2). Specifically, with regard to $\mathrm{PCS}, \mathrm{PF}$ and $\mathrm{BP}$ showed a significant gain; and with regard to $\mathrm{MCS}, \mathrm{VT}, \mathrm{SF}$, and $\mathrm{MH}$ subscales improved. On the whole, the highest enhancement in PCS obtained by our TG is very interesting because, as highlighted in other research assessing validation norms of SF-36 components

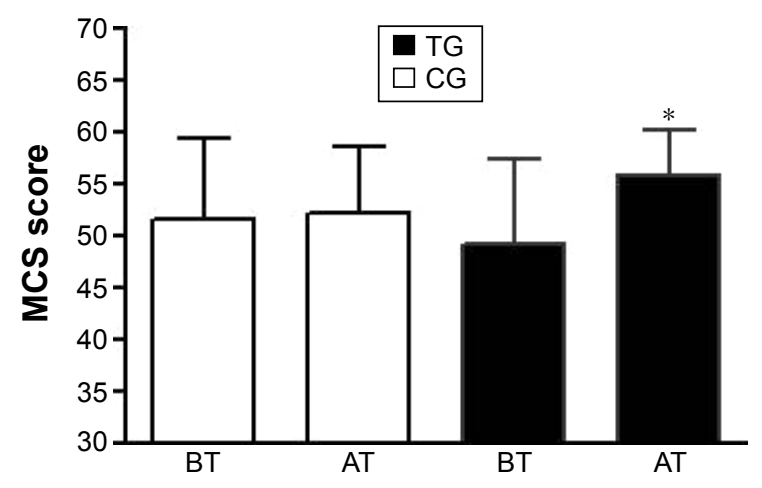

Figure 3 Mean score of mental component summary (MCS-12) of the SF-36 Health Survey in the BT and AT period in TG and CG.

Note: ${ }^{*} p<0.05$.

Abbreviations: BT, before training; AT, after training; TG, trained group; CG, control group; MCS, mental component summary; SF, short form. for age groups, PCS items seem to be more discriminating for older compared with younger women. ${ }^{15}$ Moreover, this result is consistent with clinical studies that argued how scales, such as PF and BP, loading highest on the physical component are considered to be mainly influenced by treatment targeting physical skills. ${ }^{16,17}$ So, we interpreted this improvement of PCS in our study as a demonstration of the efficacy of our exercise program.

In detail, if we look at specific subscales, the improvements in PF and BP abilities, in conjunction with better scores in VT, are related not only to general physical health but also to specific beliefs with reference to the costs and benefits of exercise in late life. A perceived poor physical health and the pain of falls or other impairments, associated to the aging process, are frequently reported as main barriers to the engagement in physical activity by older adults. ${ }^{18}$

Moreover, we think it is quite interesting to show that, with regard to the mental component measures, our TG improved their scores in $\mathrm{MH}$ and SF. These results support the crucial role of exercise training programs in promoting well-being and social inclusion among special population as the elderly. First, the MH scale has been revealed to be highly discriminant in screening for psychiatric disorders, especially depressive disorders. ${ }^{19}$ Consequently, the improvement in this subscale can be interpreted as a factor protecting our participants from the risk of developing a psychiatric disorder. On the other hand, the significant gain in SF confirms how the exercise training program is perceived as an opportunity to socialize, develop social skills by fun and leisure activities, and build a social network with other people sharing similar life experiences.

Group interface and socialization resulting from the intervention could have influenced PF, BP, and MH domains. Satisfaction and the adherence to an exercise period are crucial in order to mediate the functional and psychological changes desired. Though we did not evaluate the level of gratification during the experimental period, we found that trained participants attended at least $80 \%$ of exercise training period. Our positive percentage of attendance is inconsistent with general dropout rates estimated as $50 \%$ from the third to the sixth month of training exercise programs targeting older individuals. ${ }^{20}$ Moreover, qualitative report during feedback phase of training unit also indicated the group setting was useful and motivational. Additional study could compare groupbased and individual treatment outcomes. The multifaceted intervention had many components that could have improved MH subscales. Self-management approaches and life skills, including goal setting and researching local physical activity 
opportunities may have had an impact on QOL in elderly people. It is known, indeed, that augmented physical activity is also associated with improvement in QOL. ${ }^{21}$ A 25-week APA program improved static balance, functional mobility, as well as PF, VT, and general health subdomains of QOL in community-dwelling older women. ${ }^{6}$

\section{Conclusion}

In conclusion, our results showed that an 8-week flexibilitytraining APA program is able to improve psychophysical heath in the elderly significantly. During the aging process, a dynamic lifestyle, including regular physical activity, is a crucial factor for public and health care systems in order to improve QOL and physical fitness in aging people.

\section{Acknowledgment}

The authors would like to thank all participants involved in the study.

\section{Disclosures}

The authors report no conflicts of interest in this work.

\section{References}

1. Taricco M, Dallolio L, Calugi S, et al. Impact of adapted physical activity and therapeutic patient education on functioning and quality of life in patients with postacute strokes. Neurorehabil Neural Repair. 2014;28(8):719-728.

2. Aijo M, Heikkinen E, Schroll M, Steen B. Physical activity and mortality of 75-year-old people in three Nordic localities: a five-year follow-up. Aging Clin Exp Res. 2002;14(3 Suppl):83-89.

3. Hongo M, Itoi E, Sinaki M, et al. Effect of low-intensity back exercise on quality of life and back extensor strength in patients with osteoporosis: a randomized controlled trial. Osteoporos Int. 2007;18(10):1389-1395.

4. Smith RL, Mell DB. Effects of prone spinal extension exercise on passive lumbar extension range of motion. Phys Ther. 1987;67(10): $1517-1521$.

5. Bellafiore M, Battaglia G, Bianco A, Paoli A, Farina F, Palma A. Improved postural control after dynamic balance training in older overweight women. Aging Clin Exp Res. 2011;23(5-6):378-385.

6. Kovacs E, Sztruhar Jonasne I, Karoczi CK, Korpos A, Gondos T. Effects of a multimodal exercise program on balance, functional mobility and fall risk in older adults with cognitive impairment: a randomized controlled single-blind study. Eur J Phys Rehabil Med. 2013;49(5): 639-648.
7. Imagama S, Matsuyama $\mathrm{Y}$, Hasegawa $\mathrm{Y}$, et al. Back muscle strength and spinal mobility are predictors of quality of life in middle-aged and elderly males. Eur Spine J. 2011;20(6):954-961.

8. Battaglia G, Bellafiore M, Caramazza G, Paoli A, Bianco A, Palma A. Changes in spinal range of motion after a flexibility training program in elderly women. Clin Interv Aging. 2014;9:653-660.

9. Peluso MA, Guerra de Andrade LH. Physical activity and mental health: the association between exercise and mood. Clinics (Sao Paulo). 2005;60(1):61-70.

10. Alesi M, Bianco A, Padulo J, et al. Motor and cognitive development: the role of karate. Muscles Ligaments Tendons J. 2014;4(2):114-120.

11. Imagama S, Hasegawa $Y$, Matsuyama $Y$, et al. Influence of sagittal balance and physical ability associated with exercise on quality of life in middle-aged and elderly people. Arch Osteoporos. 2011;6:13-20.

12. Hirano K, Imagama S, Hasegawa Y, Wakao N, Muramoto A, Ishiguro N Impact of spinal imbalance and back muscle strength on locomotive syndrome in community-living elderly people. J Orthop Sci. 2012; 17(5):532-537.

13. Leon-MunozLM, Martinez-GomezD, Balboa-Castillo T, Lopez-GarciaE, Guallar-Castillon P, Rodriguez-Artalejo F. Continued sedentariness, change in sitting time, and mortality in older adults. Med Sci Sports Exerc. 2013;45(8):1501-1507.

14. Imayama I, Alfano CM, Cadmus Bertram LA, et al. Effects of 12-month exercise on health-related quality of life: a randomized controlled trial Prev Med. 2011;52(5):344-351.

15. Mishra G, Schofield MJ. Norms for the physical and mental health component summary scores of the SF-36 for young, middle-aged and older Australian women. Qual Life Res. 1998;7(3):215-220.

16. Kantz ME, Harris WJ, Levitsky K, Ware JE, Davies AR. Methods for assessing condition-specific and generic functional status outcomes after total knee replacement. Med Care. 1992;30(5 Suppl):MS240-MS252.

17. Ware JE, Gandek B. Overview of the SF-36 health survey and the international quality of life assessment (IQOLA) project. J Clin Epidemiol. 1998;51(11):903-912.

18. Schutzer KA, Graves BS. Barriers and motivations to exercise in older adults. Prev Med. 2004;39(5):1056-1061.

19. Berwick DM, Murphy JM, Goldman PA, Ware JE, Barsky AJ, Weinstein MC. Performance of a five-item mental health screening test. Med Care. 1991;29(2):169-176.

20. Lee LL, Arthur A, Avis M. Using self-efficacy theory to develop interventions that help older people overcome psychological barriers to physical activity: a discussion paper. Int J Nurs Stud. 2008;45(11): 1690-1699.

21. Gregg EW, Beckles GL, Williamson DF, et al. Diabetes and physical disability among older U.S. adults. Diabetes Care. 2000;23(9): $1272-1277$.
Clinical Interventions in Aging

\section{Publish your work in this journal}

Clinical Interventions in Aging is an international, peer-reviewed journal focusing on evidence-based reports on the value or lack thereof of treatments intended to prevent or delay the onset of maladaptive correlates of aging in human beings. This journal is indexed on PubMed Central, MedLine,

\section{Dovepress}

CAS, Scopus and the Elsevier Bibliographic databases. The manuscript management system is completely online and includes a very quick and fair peer-review system, which is all easy to use. Visit http://www.dovepress. com/testimonials.php to read real quotes from published authors. 